\title{
A reliable DNA barcode reference library for the identification of benthic invertebrates: essential for biomonitoring of the North Sea
}

\author{
Magdalini Christodoulou, Berry van der Hoorn§, Laure Van den Bulckel, Sofie Deryckel, Annelies De \\ Backerl, Ingrid Krönckeף, Pedro Martinez Arbizu ${ }^{\ddagger}$ \\ ‡ German Centre of Marine Biodiversity, Senckenberg am Meer, Wilhelmshaven, Germany \\ $\S$ Naturalis Biodiversity Center, Leiden, Netherlands \\ | Animal Sciences, Flanders Research Institute for Agriculture, Fisheries and Food, Oostende, Belgium \\ II Marine Research, Senckenberg am Meer, Wilhelmshaven, Germany
}

Corresponding author: Magdalini Christodoulou (magdalini.christodoulou@senckenberg.de)

Received: 25 Feb 2021 | Published: 04 Mar 2021

Citation: Christodoulou M, van der Hoorn B, Van den Bulcke L, Derycke S, De Backer A, Kröncke I, Martinez Arbizu P (2021) A reliable DNA barcode reference library for the identification of benthic invertebrates: essential for biomonitoring of the North Sea. ARPHA Conference Abstracts 4: e65063.

https://doi.org/10.3897/aca.4.e65063

\begin{abstract}
Benthic macroinvertebrates are key components in environmental impact assessments. Nevertheless, their use as bioindicators can be constrained by the time- and costconsuming processes needed for their morphological identification. The recent advances in high-throughput sequencing, particularly DNA metabarcoding can provide an alternative to morphology-based approaches. The main limitation for DNA-based tools to be implemented in biomonitoring projects is the considerable investment needed to build highquality and curated taxonomic reference DNA sequence libraries for species identification. To begin addressing this shortage, Interreg NSR project GEANS aim in developing a curated DNA reference library based on mitochondrial cytochrome c oxidase subunit I (COI) for the North Sea macrobenthos that will serve as the backbone of all the molecular protocols. For the collection of the macroinvertebrates, a targeted sampling campaign is underway across the North Sea Region, while existing collections are being scanned. Macrobenthic specimens are being processed following a series of standardised work flows covering sampling, morphological identifications, molecular lab processing and data
\end{abstract}


handling. GEANS' reference library, currently holds DNA barcodes for 3443 specimens collected from various areas of the North Sea. In total 11 phyla, 28 classes, 80 orders, 280 families, 428 genera and 586 species (37 non-indigenous species) are represented within the library. Species-level identification is taxonomically verified for over $90 \%$ of the species, while genus-level identifications are verified for almost $100 \%$ of the genera. GEANS reference library covers so far over $30 \%$ of North Sea species and its constantly enriched. All specimens are photographed and together with the accompanying sequences, collection and taxonomic data are archived in a dedicate BOLD project. Voucher specimens and DNA extracts are archived at three different institutes in Germany (Senckenberg am Meer), the Netherlands (Naturalis) and Belgium (ILVO). Once available, this DNA-library will be based on taxonomically well-curated specimens and it will support the implementation of fast, cost-efficient and reliable DNA-based identifications and subsequently environmental health assessments in the North Sea.

\section{Keywords}

curated reference DNA library; COI, North Sea; macrobenthos; metabarcoding; biomonitoring

\section{Presenting author}

Magdalini Christodoulou

\section{Presented at}

1st DNAQUA International Conference (March 9-11, 2021) 